\title{
AMCP Partnership Forum: Driving Value and Outcomes in Oncology
}

\begin{abstract}
SUMMARY
Innovation in cancer treatment has provided a wealth of recently available therapeutic agents and a healthy drug pipeline that promises to change the way we approach this disease and the lives of those affected in the years to come. However, the majority of these new agents, many of which are targeted to specific genomic features of various tumors, may challenge the health care system's ability to afford cancer care. This innovation drives the need to focus on the value of the treatments provided to patients with cancer and on methods to optimize the efficiency of the dollars we spend, in addition to the clinical value itself. The Academy of Managed Care Pharmacy (AMCP) convened a Partnership Forum to address how to improve value and outcomes in cancer care.
\end{abstract}

In this multistakeholder forum, several areas were addressed: current methods for assessing the value of oncology products, the need for balancing population management with precision medicine, and the outlook for value-based contracting for oncology medications in managed care settings. Participants recommended ways in which stakeholders can work toward solutions in these areas. The forum brought together stakeholders from health plans, integrated delivery systems, pharmacy benefit managers, clinical practice, biopharmaceutical industry, and laboratory companies. Also participating were representatives from trade and professional associations.

During this 1.5-day forum, participants identified current challenges, readiness, and ways to address value and improve outcomes in cancer therapy. Some of the challenges identified include choosing a viable (and practical) outcome target for value-based contracting in oncology, the development and use of value frameworks and clinical pathways, managing cancer diagnostics, utilization of alternative payment systems, moving from a large evidence base to a small clinical trial base in considering targeted treatments, and lack of best practices in value-based payment arrangements. Addressing these challenges could lead to improving cancer treatment.

J Manag Care Spec Pharm. 2017;23(5):591-97

Copyright $\odot 2017$, Academy of Managed Care Pharmacy. All rights reserved.

T rends in U.S. cancer care indicate that outcomes are improving for many cancers. ${ }^{1}$ Innovations in early detection and treatment are widely assumed to play a significant role in improving outcomes but raise the question of sustained affordability. ${ }^{2}$ For these reasons, oncology is a key topic of nearly any discussion of the health care delivery system today and for the foreseeable future.

The aging of the baby boom generation is one factor in the increasing incidence of cancer diagnosis. ${ }^{3}$ At the same time, however, cancer-related mortality is decreasing (21\% lower today than in 1995), ${ }^{1}$ which is largely attributable to early detection and new treatments. The result is the transformation of many cancers from acute to chronic diseases. ${ }^{4}$

Total expenditures in cancer care in 2010 were calculated to be $\$ 124.6$ billion. Expenditures for cancer care in 2020 have been estimated to be $\$ 157.8$ billion and as high as $\$ 174$ billion. ${ }^{5,6}$
However, recent data suggest that the growth in actual cancer costs may be leveling off (partly the result of the recession). ${ }^{7}$ One area of cancer care spending that is increasing is novel therapies, many of which lead to substantially better outcomes for patients but may also carry high price tags. For example, there is intense interest in the potential for new immunotherapies, but appropriate patient selection will be needed to optimize their use, since the list price for some agents may be more than $\$ 270,000$ annually. ${ }^{2,8,9}$ As a result, health system stakeholders are beginning to seek ways to optimize the efficiency of the dollars we spend.

\section{Several Approaches to Value in Oncology}

Although the simplest expression of value may be outcomes divided by cost, this approach is rarely straightforward in health care-and cancer care in particular. With several ways to consider and calculate value and many variables used in the calculations (Table 1), it is not surprising that available tools and models are not yet widely adopted..$^{10}$

In a small survey of approximately 100 medical oncologists/ hematologists, the majority of respondents did not use value models in making treatment decisions today. ${ }^{10}$ Also, it is not clear how soon the majority of payers will use value frameworks in their own value and coverage decisions.

\section{About the Partnership Forum}

The Academy of Managed Care Pharmacy (AMCP) convened the Partnership Forum "Driving Value and Outcomes in Oncology," which was held November 15-16, 2016, in Dulles, Virginia. Participants represented health plans, integrated delivery systems, pharmacy benefit managers, clinical practice, the biopharmaceutical industry, and laboratory companies. Trade and professional associations were also represented.

The forum participants addressed current methods for evaluating oncology products and companion diagnostics, the need to balance population management with precision medicine, the outlook for risk-based or indication-specific contracting in oncology, and the challenges and opportunities with the utilization of emerging evaluation and treatment tools in managed care settings.

During the forum, participants were divided into workshop groups. Each group was asked to address the same prespecified questions around 3 topics. The results of the workgroup discussions are summarized by topic as follows: opportunities and challenges with oncology valuation, value-based contracting in oncology, and precision medicine/pharmacogenomics.

\section{Oncology Valuation: Opportunities and Challenges}

Forum participants were asked about oncology management challenges for managed care decision makers. They discussed how payers' goals for oncology management were evolving, 


\begin{tabular}{|c|c|c|}
\hline Organization & $\begin{array}{l}\text { Name of Tool/ } \\
\text { Approach }\end{array}$ & Definition or Value Assessment Approach \\
\hline $\begin{array}{l}\text { American Society of Clinical } \\
\text { Oncology (ASCO) }\end{array}$ & $\begin{array}{l}\text { Value } \\
\text { Framework }\end{array}$ & $\begin{array}{l}\text { Calculates a "net health benefit" based on clinical effectiveness, toxicity, and additional improvements in } \\
\text { treatment-free interval, cancer symptoms, survival curve, or quality of lifell }\end{array}$ \\
\hline $\begin{array}{l}\text { Institute for Clinical and } \\
\text { Economic Review (ICER) }\end{array}$ & N/A & $\begin{array}{l}\text { Not an oncology-specific value framework but has published assessments of multiple myeloma, non-small } \\
\text { cell lung cancer, and prostate cancer. Reviews performed by ICER result in the estimation of cost- } \\
\text { effectiveness ratios (cost per quality-adjusted life-year) }{ }^{19}\end{array}$ \\
\hline Institute of Medicine & N/A & $\begin{array}{l}\text { Definition of value in oncology has } 6 \text { separate components: safety, effectiveness, timeliness, patient } \\
\text { centeredness, efficiency, and equity } 20\end{array}$ \\
\hline Memorial Sloan Kettering & DrugAbacus & $\begin{array}{l}\text { Calculates the "Abacus Price" or relative value of an intervention based on efficacy, toxicity, innovative } \\
\text { nature of the therapy, cost of development, the frequency of the disease, unmet need, prognosis, and the } \\
\text { population burden of disease } 21\end{array}$ \\
\hline $\begin{array}{l}\text { National Comprehensive } \\
\text { Cancer Network (NCCN) }\end{array}$ & $\begin{array}{l}\text { NCCN Evidence } \\
\text { Blocks }\end{array}$ & $\begin{array}{l}\text { Considers treatment efficacy, safety, quality and consistency of evidence supporting the guideline-based } \\
\text { therapy or regimen, and its affordability as a pictogram so that treatment choices can be informed by the } \\
\text { patient's own values } 22\end{array}$ \\
\hline
\end{tabular}

together with the role that oncology pathways and frameworks may play in product evaluation, quality, and financial stewardship. The key issues and considerations that were discussed are listed under the following categories: disease, information, and structure.

\section{Disease}

- No consensus definition of value in cancer care. As previously noted, several varied approaches exist for the systematic valuation of value. The elements chosen by the Institute of Medicine to define value are subjective ${ }^{11}$; incremental costeffectiveness ratios could be applied to oncology product valuations, but in the United States, we have not set standards for how these measures should be used.

- Cancer is not a single disease. Cancer represents a heterogeneous class of disorders that vary by tumor type, stage, location, and genomic characteristics. Therefore, the value of treatment may also vary with these dimensions.

- Acute to chronic shift. Our success in obtaining remission and in delaying the progression of many cancers has resulted in their transformation from acute to chronic conditions. This requires a change in payer planning for the long-term impact of oncology therapy on quality of life, future health care needs, and insurance benefits.

- From patient compassion to "economic dispassion." Employers pay for roughly half of the health expenditures in the United States, and chief financial officers are now more engaged in the discussions of employer-sponsored health benefits. Selfinsured plans have broad ability to include or exclude specific drugs or therapeutic classes of drugs from coverage. The use of narrow pharmacy and provider networks and more limited coverage policies has begun to reflect a change from the traditional broad coverage policies to ones more focused on managing the economics of cancer care.
- Outcomes of importance. Payers, providers, manufacturers, researchers, and patients are challenged to align on which outcomes (e.g., overall survival, progression-free survival, quality of life, productivity) offer the best measure of value in cancer care.

- The value of palliative care is not well disseminated. Patients often are not informed about palliative care options until late in the course of treatment. ${ }^{12}$ Palliative care is sometimes interpreted as a denial of active treatment rather than a way to improve quality of life.

\section{Information}

- Data collection of outcomes. Another important consideration of choosing an outcome involves the practicality of realworld data collection and analysis. Outcomes are rarely reported in claims data and usually need to be captured in other ways, such through chart review.

- Quality data and evidence. Some of the clinical evidence on which cancer therapy is based is on the highest level of clinical evidence and consensus possible (i.e., guidelines usually assign this as Grade A or Category 1 evidence). But for the most part, expert consensus and lower-level evidence form the foundation of many of the treatment guidelines today.

- Consistent treatment pathways and guidelines. There is a desire for consistent treatment pathways and guidelines that are transparent, evidence based, complete, and updated in a timely manner but, at the same time, allow physicians to make patient care decisions based on patient-specific characteristics.

- Genomic sequencing. Advances in genomic evaluation and increases in the accessibility of testing have resulted in opportunities for precision medicine. In the absence of large clinical trial data, it is not often clear if available drug therapies approved for targeting a genomic variant for one cancer will produce the same effect in a patient with the same genomic variant but a different cancer diagnosis. Basket trials 
(e.g., TAPUR, MATCH), which evaluate cancer therapies against specific mutations (not tumor type or location), represent an opportunity to fill this evidence gap. ${ }^{13-15}$

- Need to account for new innovations. Value frameworks and clinical pathways will need to be updated regularly to consider new technologies, indications, and clinical trial and real-world data. However, new therapies will need to generate a sufficient body of evidence to allow for appropriate comparisons to current standards of care. Alternative payment models will need to consider how new innovations may alter treatment costs and reimbursements.

Structure

- Most value assessment tools are not ready for implementation. Forum stakeholders remain challenged regarding how the value of health care treatments-especially medicinesshould be assessed and whether existing value assessment frameworks utilize appropriate measures. The American Society of Clinical Oncology (ASCO) states that its value framework is still in development and not ready for implementation. ${ }^{16}$ Participants acknowledged the risks in publishing and using value assessment tools before testing and validation are completed. Participants expressed a need for understanding the methods used to develop the tools and the key drivers behind the tools' results.

- Patient centeredness. Physicians seek to be able to prescribe the most appropriate treatments for each individual patient at any stage of their disease progression.

- Aligning incentives. Stakeholders are seeking clinical pathways and value assessment tools that do not dictate but materially inform the treatment selection process. The objectives of these tools are to decrease unnecessary variability in practice and to improve care, quality, and affordability. Physician buy-and-bill payment designs and consolidation of physician practices may also affect incentives and overall health care spending.

- Data and value fragmentation. Without the ability to collect data from electronic health records (EHRs) and utilization data from other clinical sources, effective use of value assessment may not be viable. Challenges were identified regarding the interoperability, coordination, and sharing of data across different departments within organizations.

\section{Value-Based Contracting in Oncology}

Given the role that prescription drugs play in the treatment of, and spending for, oncology, health plans and manufacturers seek greater opportunities to align payment with quality, accountability, and care coordination. Value-based contracts can include outcomes-based contracts, risk-based contracts, indication-specific pricing, and other innovative contracting designs. Participants were asked to determine how data infrastructure and analytic models support these innovative contracts and to identify gaps in information that need to be addressed to better assess the success of these contracts. The critical considerations are categorized as legal, measurement, and transparency.

Legal

- Support open communication. For indication-specific contracts, the contract terms are limited to the labeled indications approved by the U.S. Food and Drug Administration (FDA); however, for many oncology agents, off-label usage is common. A safe harbor that is clear and supported by peerreviewed literature would have to be created to allow pharmaceutical companies to share information outside of the product labeling with payers. This would support discussions of a broader range of off-label uses during value-based contracting negotiations. It should also support sharing of information pre-approval and contracting on outcomes related to approved indications.

- Average sales price and best-price reporting requirements. The participants believe that clarifications-and, if needed, exceptions-for average sales price (ASP) and best-price reporting requirements and safe harbors to the federal antikickback statute may be helpful. ${ }^{17}$ This would protect parties involved in the negotiation of value-based contracts.

- The anti-kickback statute prohibits offering or receiving remuneration to induce or reward referrals for items or services paid for by federal health care programs. Statutory exceptions and regulatory safe harbors protect certain arrangements from liability, but it is unclear how enforcement agencies would apply these exceptions and safe harbors to value-based arrangements.

- Medicaid best price is the pricing benchmark used to ensure state Medicaid programs do not pay more than the lowest price offered for a particular therapy. ${ }^{18}$ In general, best price is affected by rebates, discounts, or other price concessions to commercial health plans. Under the current regulations, payments from manufacturers to health plans under a value-based contract would likely need to be included in best-price calculations. The best-price statute and regulations could be clarified to consider certain rebates and price concessions that are the result of value-based contracting (e.g., rebates paid if a patient does not respond to treatment).

- ASP reporting may also be a factor limiting value-based contracts. For Medicare Part B-covered drugs, manufacturers are required to report ASP to set Medicare Part B reimbursement rates. Manufacturers may be concerned that rebates offered to health plans under value-based contracts would reduce ASP and, in turn, Medicare Part $B$ reimbursement rates.

\section{Measurement}

- Exchanging health information. Implementing value-based contracts requires exchange of health information among providers, payers, and drug manufacturers.

- Defining measurable outcomes. The challenge is to identify meaningful and measurable outcomes that can be analyzed 
with little administrative burden. Furthermore, the time horizons for chosen outcomes must consider the typical duration of plan enrollment. For example, choosing a 5-year period for measuring overall survival may not be practical in a health plan population that turns over on average every 3 years.

- Consider the patient. Payers may want to connect the value of oncology care from the patient's perspective (e.g., plans could incentivize patients for using interventions deemed to provide more value; therefore, the value proposition is more apparent).

- Lack of consensus on valued outcomes in oncology. Different stakeholders have varying perspectives on outcomes, or surrogates, of importance for measuring value. Payers, providers, manufacturers, researchers, and patients are challenged to align on which outcomes offer the best measure of value in cancer care.

- Operational complexity. The costs associated with increased monitoring, interoperability issues, and ensuring patient privacy may outweigh the potential benefits from valuebased contracts. To alleviate the administrative burdens of recording data, data reporting, and analysis, contracts should be constructed to require the least amount of operational complexity as possible. Health information technology systems may have the capability of reducing the need for staff input and analysis. Developers of EHR systems will likely play a key role in addressing the capabilities of data reporting, management, and analysis that would support value-based contracts. Another solution may be to use a web-based application (which is EHR agnostic) to collate the relevant data.

- Data availability and accuracy. The divide between medical and pharmacy data in many health systems must be bridged in order to obtain the information necessary to complete the clinical picture for analysis of drug performance and patient outcomes.

- Limited patient populations. In oncology, the specific populations of patients for some payers may be too small to yield statistically meaningful and measurable population-wide results, thus limiting the viability of value-based contracts for these organizations.

- Limited evidence on best practices. Limited evidence exists with regard to best practices for developing and implementing value-based contracts. Areas of key importance include simplifying the tracking and measurement of patient outcomes: consider the abilities of payers/clinicians to record and analyze specific data elements.

Transparency

- Need to address information asymmetry. The pharmaceutical manufacturer usually has more information on drug performance compared with the published information available to providers and health plans. This relates to regulatory restrictions on manufacturers sharing information on offlabel uses. Health plans are well positioned to evaluate evidence and consider any existing limitations in evidence for off-label use.

- Contract evaluation and audit. The risk-sharing parties will need to periodically audit clinical information (without violating HIPAA rules on personal health information). A trusted third party could analyze the outcomes specified in the contract and determine if the contract terms were met.

- Outcomes analysis. How clinical data are collected, analyzed, and tied to outcomes in risk-sharing contracts is not generally shared outside of the risk-sharing parties. Therefore, education and best practice sharing could result in a better understanding of these key elements of contract analysis and success.

\section{Precision Medicine and Pharmacogenomics}

A movement away from treating each tumor according to its location in the body and toward treatment based on its individual genetic and molecular characteristics-the genetic mutations specific to that tumor-is on the leading edge. The ability to determine the genome of tumors, affordably and quickly, has brought the promise of precision medicine to cancer treatment. Yet, the medical community faces challenges in a number of areas before precision medicine can provide not only consistently superior outcomes but also improved value in cancer care. These challenges can be grouped into 3 categories: preparation, utilization, and evolution.

Preparation

- Staying current with new evidence. Population health decision makers will need to keep apprised of developments in this fast-changing area. It will be critical to understand how precision medicine may be applied to medications and diagnostic tools in the oncology pipeline.

- Aligning benefits. The participants acknowledged that coverage by payers will follow the emerging evidence. However, several questions must be answered, including who requests the diagnostic testing, what treatment or prognostic decisions can be made based on the results of the tests, and when to use discrete or limited testing versus broad panel testing.

- Managing expectations. Providers need educational tools for patients to help them differentiate the promise from the reality of genomic testing today. This relates also to whether treatments currently exist that can target mutations identified through genomic testing.

Utilization

- Integrating decision-support tools. The development of decision-support tools, incorporated into EHRs, will assist in appropriate use of diagnostic tests. Ideally, the EHR will incorporate electronic coverage decision support and clearly show which diagnostic tests are warranted.

- Broad genomic testing versus specific diagnostics. Should all oncology patients receive broad panel testing, or are tests for specific genomic variants more appropriate and cost effective? Comprehensive genomic profiling is not intended 


\section{TABLE 2 Potential Roles for AMCP and Key Stakeholders in Driving Value and Outcomes in Oncology}

\begin{tabular}{|c|c|}
\hline $\begin{array}{l}\text { Potential roles in } \\
\text { the valuation of } \\
\text { cancer care }\end{array}$ & $\begin{array}{l}\text { - Develop third-party certification of clinical pathways and creation of a structure around them, including producing best } \\
\text { practices for their implementation, including data collection. } \\
\text { - Better integration and use of palliative care by improving communications between providers and patients regarding its benefits. } \\
\text { - Seek to improve definitions and measurement of quality in oncology to better support biopharmaceutical development and } \\
\text { research and inform better value assessment. } \\
\text { - Create standards for oncology cost-effectiveness studies and develop an oncology e-dossier. } \\
\text { - Share information on, and results of, value-based efforts undertaken in other countries. } \\
\text { - Help engage patients in education about value in cancer care. }\end{array}$ \\
\hline $\begin{array}{l}\text { Value-based } \\
\text { contracting in } \\
\text { oncology }\end{array}$ & $\begin{array}{l}\text { - Publish best practices in innovative contracting for oncology services, including how to administer the contract program and } \\
\text { the infrastructure needed. } \\
\text { - Focus efforts on regulatory and legislative barriers, including best price regulations, anti-kickback safe harbors, and in support } \\
\text { of expanding the use of value-based contracting. } \\
\text { - Advocate for consistent and better outcome measures in oncology and standardize the operations of data collection. }\end{array}$ \\
\hline $\begin{array}{l}\text { The promise of } \\
\text { precision medicine } \\
\text { in oncology }\end{array}$ & $\begin{array}{l}\text { - Educate payers and providers about the pipeline for new genetic testing and targeted oncology medications and interpretation of } \\
\text { genetic testing results. } \\
\text { - Create a credible compendium or database of scientific information around the use of diagnostics and precision medicine. } \\
\text { - Promote efficient testing and treatment and support ways to expedite the coverage determination processes, including the use of } \\
\text { electronic prior authorization. } \\
\text { - Advocate for sensible regulation of genomic testing and companion diagnostics. } \\
\text { - Engage laboratory stakeholders and laboratory testing associations to increase their awareness of managed care challenges } \\
\text { around key issues regarding utilization, reimbursement, and determinants of the value of diagnostic tests. }\end{array}$ \\
\hline
\end{tabular}

AMCP = Academy of Managed Care Pharmacy.

for all patients. Consideration for comprehensive genomic profiling should be reserved for patients where there is documented clinical rationale.

- Interpreting genetic testing results and implications. Multiple stakeholders will need information on what these results mean and whether they are actionable. In some cases, genomic variants identified by the tests may not be driving cancer growth. Therefore, treatment targeting the variant will not ensure successful treatment outcomes. In other cases, the identified variants may indeed be a factor in cancer progression, but targeted medical treatments are not available.

- Defining experimental therapy. The choice of treatment based on the broad use of diagnostic testing in areas not supported by evidence may be considered experimental therapy and not covered by payers.

\section{Evolution}

- Small trial populations. Clinical trials of precision medicine will use relatively small patient populations. In the short term, managed care coverage decisions will need to be based on this limited body of evidence. The analysis of specific interventions may be bolstered through reporting systems that capture data and outcomes from real-world evidence (e.g., CancerLinq).

- Greater regulatory focus. Regulation of laboratory-developed tests is the purview of the FDA (laboratory tests are considered devices). Until there is further regulation in this emerging sector, decision makers will need to carefully evaluate the evidence for each test, including its clinical utility and the validity of its clinical and analytical data.

- Melding population management with precision medicine. Precision medicine can help increase the precision of population health management. The evolution of new quality measures based on the use of genetic testing may also drive population health management. A more efficient electronic prior authorization process may help to lessen administrative burdens while speeding precision medicine treatment access to individual patients.

\section{Conclusions}

Although multiple challenges exist in defining value in oncology care, avenues are available to leverage technology-based and market-based solutions to help payers, physicians, and the health system improve care quality, clinical outcomes, and economic efficiency. Table 2 represents the Partnership Forum participants' suggested paths to solutions and ways in which the various organizations (e.g., health plans, associations, biopharmaceutical companies) can assist or facilitate the current and future implementation of value-based payment arrangements, precision-based medicine, population-based medicine, and tools for addressing value in cancer therapy. These suggestions will require better use of the clinical evidence in cancer care to improve the collection and connectivity of information and the dissemination for best practice development. 


\section{Forum Participants}

RACHEL ANHORN, PharmD, Director, Payer Medical Affairs, Foundation Medicine; TRACY BARONI ALLMON, BSPharm, JD, Executive Director, Health Policy, Novartis Oncology; REBECCA BORGERT, PharmD, BCOP, Product Development Director, Clinical Oncology, Magellan Rx Management; SEAN BUCKLEY, PharmD, BA, Regional Director of Pharmacy; HAROLD L. CARTER, PharmD, Director, Clinical Solutions, Express Scripts; LAURENT CARTER, MBA, Vice President of Strategic Payer Marketing, Bristol-Myers Squibb; BERRIE C. CHILD, PharmD, BCOP, Hematology/Oncology Clinical Pharmacist, LDS Hospital; TIM CHIU, PharmD, BCPS, Pharmacist Evidence Analyst and Strategist, Kaiser Permanente; RYAN M. COX, BSPharm, RPh, MBA, Director, Clinical Pharmacy Strategies Highmark; SUZETTE DIMASCIO, CHE, CMCE, CPC, President/CEO, CSI Specialty Group; MICHELLE DROZD, SCM, Deputy Vice President, Policy and Research, Pharmaceutical Research and Manufacturers of America; STEPHEN GRUBBS, MD, Vice President, American Society of Clinical Oncology; JAQUE MALLENDER, Partner, Public Policy, Optimity Advisors; KEVIN HOGAN, BSPharm, RPh, Clinical Pharmacist Consultant, OmedaRx (Regence Health Plan); LOUIS HUDSPETH, MS, PhD, Director, Medical Managed Care, Oncology, Sanofi; ROB JACOBSON, Executive Director, US Value and Access, Oncology, Amgen; TATYANA KAPUSTYAN, PharmD, Senior Director, Healthcare Solutions, Global Medical Affairs, AbbVie; EDWARD KISSEL, Senior Director, IntrinsiQ Analytics, IntrinsiQ Specialty Solutions; JAMES R. LANG, PharmD, MBA, Vice President, Pharmacy Services, BCBS of Michigan; KELLIE MEYER, PharmD, MPH, Senior Director, Global Health Economics and Outcomes Research, Xcenda; DONNA MONCUSO, MS, RN, Director of Payor and Employer Outreach, National Comprehensive Cancer Network; THERESE M. MULVEY, MD, FASCO, Breast Oncology Medical Director, MGH North Shore, Massachusetts General Hospital; ANN NGUYEN, PharmD, Oncology Solutions Director, Anthem; GARY M. OWENS, MD, President, Gary Owens Associates; COREY PELLETIER, PhD, Director of US Health Economics and Outcomes Research, Celgene; SARAH SCARPACE PETERS, PharmD, MPH, BCOP, President, Hematology/ Oncology Pharmacy Association; NISHA PHERWANI, PharmD, BCOP, Clinical Director, Oncology, Cardinal Health; RAMI RIHANI, PharmD, Administrator of Pharmacy and Chronic Disease Management, Advocate Health Care; JOSHUA ROTH, MHA, PhD, Assistant Member, Hutchinson Institute for Cancer Outcomes Research, Fred Hutchinson Cancer Research Center, and Affiliate Assistant Professor, Department of Pharmacy, University of Washington; SCOTT SHORTENHAUS, Director, PACE USA, Policy and Advocacy, Lilly Oncology; KIMBERLY WESTRICH, MA, Vice President, Health Services Research, National Pharmaceutical Council; SUSAN C. WINCKLER, RPh, Esq, Chief Risk Management Officer, Leavitt Partners (moderator); ANDREW K. YU, PharmD, BCOP, Oncology Coordinator, Group Health; and SUSAN ZELT, DrPH, MBA, MPH, Senior Director, Takeda Oncology.

AMCP STAFF: SUSAN A. CANTRELL, RPH, CAE, Chief Executive Officer; MARY JO CARDEN, RPh, JD, Vice President of Government and Pharmacy Affairs; EMILY DELAUDER, Project Coordinator, Business Development; CHARLIE DRAGOVICH, BSPharm, Senior Director of Business Development and Strategic Alliances; NEAL LEARNER, Media Relations and Editorial Director; CHRIS LYONS, Chief Operating Officer; DANA REGAN, MBA, Senior Vice President, The Access Group; TERRY RICHARDSON, PharmD, BCACP, Director of Product Development; and RUBY SINGH, PharmD, BCPS, Vice President, Education and Training.

CORRESPONDENCE: Terry Richardson, PharmD, BCACP, Director of Product Development, Academy of Managed Care Pharmacy, 675 N. Washington St., Ste. 220, Alexandria, VA 22314.

E-mail: trichardson@amcp.org.

\section{DISCLOSURES}

The AMCP Partnership Forum titled "Driving Value and Outcomes in Oncology" and the development of this report were supported by AbbVie, Amgen, Bristol-Myers Squibb, Celgene, Foundation Medicine, IntrinsiQ Specialty Solutions, Janssen Oncology and Johnson and Johnson Health Systems, Eli Lilly and Company, National Pharmaceutical Council, Novartis Pharmaceuticals Corporation, Pharmaceutical Research and Manufacturers of America, Sanofi, Takeda Oncology, and Xcenda.

\section{ACKNOWLEDGMENTS}

AMCP and the forum participants thank Stanton R. Mehr, SM Health Communications, for his services in developing this proceedings report.

\section{REFERENCES}

1. Howlader N, Noone AM, Krapcho M, et al., eds. SEER cancer statistics review, 1975-2013. National Cancer Institute. 2016. Available at: http://seer. cancer.gov/csr/1975_2013/. Accessed March 20, 2017.

2. American Society of Clinical Oncology. State of cancer care in America: 2016 (infographic). 2016. Available at: http://www.cancer.net/blog/2016-03/ state-cancer-care-america-2016-report-finds-unprecedented-opportunityamid-profound-turbulence. Accessed March 20, 2017.

3. Bluethmann SM, Mariotto AB, Rowland, JH. Anticipating the "silver tsunami": prevalence trajectories and comorbidity burden among older cancer survivors in the United States. Cancer Epidemiol Biomarkers Prev. 2016;25(7):1029-36

4. American Cancer Society. Managing cancer as a chronic illness. Available at: http://www.cancer.org/treatment/survivorshipduringandaftertreatment/ when-cancer-doesnt-go-away. Accessed March 20, 2017.

5. Mariotto AB, Yabroff KR, Shao Y, et al. Projections of the cost of cancer care in the United States: 2010-2020. J Natl Cancer Inst. 2011;103(2):117-28.

6. National Cancer Institute. Cancer prevalence and cost of care projections. Available at: https://www.costprojections.cancer.gov/expenditures.html. Accessed March 20, 2017

7. Lee JA, Roehrig CS, Butto ED. Cancer care cost trends in the United States: 1998 to 2012. Cancer. 2016;122(7):1078-84.

8. Boulart BHL. Value: the next frontier in cancer care. Oncologist. 2016;21(6):651-53.

9. Kantajarian HM, Fojo T, Mathisen M, et al. Cancer drugs in the United States: justum pretium—the just price. J Clin Oncol. 2013;31(28):3600-04.

10. Lederman L. Value tools at ASCO 2106: Building a framework for prime time. ZS Associates. 2016. Available at: http://www.zsassociates.com/publications/articles/value-tools-at-asco-2016-building-a-framework-for-primetime.aspx. Accessed March 20, 2017

11. Schnipper LE, Davidson NE, Wollins DS, et al. American Society of Clinical Oncology statement: a conceptual framework to assess the value of cancer treatment options. J Clin Oncol. 2015;33(23):2563-77.

12. Centers for Medicare \& Medicaid Services. Medicare care choices model. July 28, 2016. Available at: https://innovation.cms.gov/initiatives/MedicareCare-Choices/. Accessed March 20, 2017.

13. American Society of Clinical Oncology. Targeted Agent and Profiling Utilization Registry [TAPUR] study: about the TAPUR study. Available at: http://www.tapur.org/. Accessed March 20, 2017.

14. National Cancer Institute. NCI-Molecular Analysis for Therapy Choice (NCI-MATCH) Trial. Available at: https://www.cancer.gov/about-cancer/ treatment/clinical-trials/nci-supported/nci-match. Accessed March 20, 2017.

15. Redig AJ, Jänne PA. Basket trials and the evolution of clinical trial design in an era of genomic medicine. J Clin Oncol. 2015;33(9):975-77. 
16. Cavallo J. ASCO releases the updated version of its Value Framework: a conversation with Lowell E. Schnipper, MD. June 25, 2016. Available at: http://www.ascopost.com/issues/june-25-2016/asco-releases-the-updatedversion-of-its-value-framework/. Accessed March 20, 2017.

17. Criminal penalties for acts involving federal health care programs (AntiKickback Statute). Public Health Services Act. 42 U.S.C. \$1320a-7b(b).

18. Payment for covered outpatient drugs: Requirement for rebate agreement. Social Security Act Section 127 (c)l(C). 42 U.S.C. \$1396r-8.

19. Institute for Clinical and Economic Review. Topics. Available at: https:// icer-review.org/topics/. Accessed March 20, 2017.
20. Institute of Medicine; Board on Health Care Services; Committee on Improving the Quality of Cancer Care, et al., eds. Delivering High-Quality Cancer Care: Charting a New Course for a System in Crisis. Washington, DC National Academies Press; 2013.

21. Memorial Sloan Kettering Cancer Center. DrugAbacus: methods. Available at: http://www.drugabacus.org/drug-abacus/methods/. Accessed March 20, 2017.

22. National Comprehensive Cancer Network. Evidence blocks user guide. Available at: https://www.nccn.org/evidenceblocks/pdf/ EvidenceBlocksUserGuide.pdf. Accessed March 20, 2017. 